\title{
Serial Thyroid Function Test in Very Low Birth Weight Neonates
}

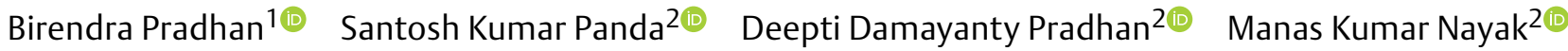 \\ Soumini Rath ${ }^{20}$ Sonali Sahoo ${ }^{30}$
}

${ }^{1}$ Department of Pediatrics, Veer Surendra Sai Institute of Medical Sciences and Research, Burla, Odisha, India

2 Department of Pediatrics, Kalinga Institute of Medical Sciences, Bhubaneswar, Odisha, India

${ }^{3}$ Department of Physiology, Veer Surendra Sai Institute of Medical Sciences and Research, Burla, Odisha, India

\begin{abstract}
Address for correspondence Birendra Pradhan, MD, Department of Pediatrics, Veer Surendra Sai Institute of Medical Sciences and Research, Sambalpur 768017, Odisha, India (e-mail: biren131@gmail.com).
\end{abstract}

J Child Sci 2021;11:e173-e177.
Abstract
Keywords
- very low birth weight infant
- thyroid function tests
- congenital hypothyroidism
- premature infants

Thyroid dysfunction is more common in preterm and low birth weight infants, and may be missed if thyroid function test (TFT) is not repeated. Thus, we attempted to study the pattern of thyroid function among very low birth weight (VLBW) infants with birth weight less than $1,500 \mathrm{~g}$ by serial TFTs. Serum free thyroxine (FT4) and thyrotropin (thyroid-stimulating hormone [TSH]) levels of VLBW infants were tested on fifth to seventh days of life and repeated after 4 weeks of age. Based on serial FT4 and TSH results, abnormal TFT was classified into four groups-transient hypothyroxinemia of prematurity (THOP), transient hyperthyrotropinemia (THT), delayed TSH rise, and overt congenital hypothyroidism (CH). Stata 15.1 (Stata Corp, Texas, United States) was used for analysis. Ninety-six VLBW infants were enrolled with mean gestational age of $30.5 \pm 2.7$ weeks and median (interquartile range) birth weight of 1,200 (317) g. Out of 96 cases, $30(31.2 \%)$ infants had abnormal TFT. Ten (10.4\%) infants had THOP, 7 (7.3\%) infants had THT, 11 (11.5\%) infants had delayed TSH rise, and $2(2.1 \%)$ infants had overt $\mathrm{CH}$. There were no significant differences in demographic profile and clinical characteristics between neonates with normal and abnormal TFTs. Five infants required levothyroxine supplementation (two infants with overt $\mathrm{CH}$ and three infants with delayed TSH rise). VLBW neonates have higher incidence of $\mathrm{CH}$ and delayed rise of TSH in this study. In resource-limited settings, repeating TFTs at least once after 4 weeks of age may be suggested to identify delayed rise of TSH which may need intervention.

\section{Introduction}

Congenital hypothyroidism $(\mathrm{CH})$ is one of the preventable causes of neurodevelopmental impairment, if diagnosed and treated early. ${ }^{1}$ Across the globe, newborn screening program has been established to identify $\mathrm{CH}^{2}$ The overall incidence of CH ranges from $1: 3,000$ to $1: 4,000$ globally and as per the Indian Council of Medical Research data, the overall incidence

received

November 29, 2020

accepted after revision

May 20, 2021
DOI https://doi.org/

$10.1055 / \mathrm{s}-0041-1731337$.

ISSN 2474-5871. of $\mathrm{CH}$ is 1:1,130 in India. ${ }^{3}$ The hypothalamic-pituitary-thyroid (HPT) axis in preterm neonates is less mature compared with term infants. Immaturity of thyroid hormone synthesis and metabolism, increased need for thyroxine by preterm neonates, and stormy course of very low birth weight (VLBW) infants influence thyroid hormone production and regulation. ${ }^{4,5} \mathrm{CH}$, transient hypothyroxinemia of prematurity (THOP), delayed rise of thyroid-stimulating hormone (TSH), (c) 2021. The Author(s).

This is an open access article published by Thieme under the terms of the Creative Commons Attribution License, permitting unrestricted use, distribution, and reproduction so long as the original work is properly cited. (https://creativecommons.org/licenses/by/4.0/)

Georg Thieme Verlag KG, Rüdigerstraße 14, 70469 Stuttgart, Germany 
and transient hyperthyrotropinemia (THT) are known thyroid disorders of premature infants. ${ }^{6}$ Thyroid dysfunctions are more common in premature and low birth weight infants as reported in various studies. Kim et al performed serial thyroid function tests (TFTs) in180 premature infants less than 32 weeks and found thyroid dysfunction in $28.9 \%$ of them. ${ }^{7}$ Similarly, Armanian et al found abnormal TFTs in $58.7 \%$ of VLBW infants. ${ }^{8}$ However, evidence-based guidelines for thyroid function monitoring in preterm neonates have not been established. Thus, our study was done to assess various thyroid function disorders in VLBW infants at our institute.

\section{Methods}

\section{Study Design}

It was a prospective study, conducted in a tertiary care neonatal intensive care unit (NICU) of a teaching hospital in Odisha between January 2017 and December 2017, after approval by institutional ethical committee. Informed written consent was obtained from the parents prior to enrollment in the study.

\section{Study Participants}

All inborn and outborn VLBW neonates with birth weight less than $1,500 \mathrm{~g}$ admitted in the NICU during the study period were enrolled. Neonates with multiple congenital anomalies, neonates who died before 4 weeks of age, and in whom TFTs could not be performed at scheduled times were excluded.

\section{Data Collection}

Neonatal mass screening program for TFT has still not been established in India. We measured serum free thyroxine (FT4) and thyrotropin (TSH) levels of VLBW neonates on fifth to seventh days of life and repeated after 4 weeks of age from $0.5 \mathrm{~mL}$ venous sample using electrochemiluminescencesandwich principle. FT4 level $<0.9 \mathrm{ng} / \mathrm{dL}$ in the first week and $<1.1 \mathrm{ng} / \mathrm{dL}$ in the fourth week were considered low. TSH level $>10 \mathrm{mU} / \mathrm{L}$ was considered abnormal. ${ }^{9}$

Demographic profile of the neonates was recorded in a predesigned pro forma. Neonates were classified as appropriate for gestational age, small for gestational age, and large for gestational age using Fenton's growth curve. Gestational age was estimated from the first day of maternal last menstrual cycle and confirmed by the new Ballard score. Neonatal diseases were managed as per unit protocol. Complete antenatal corticosteroid therapy was considered in the mother who had received two doses of intramuscular betamethasone or four doses of intramuscular dexamethasone before delivery. Ventilation without the use of endotracheal tube was considered as noninvasive ventilation. Ventilation which needs endotracheal intubation was considered as invasive ventilation except INSURE (INtubation, SURfactant therapy followed by Extubation to continuous positive airway pressure) technique for surfactant administration. Neonates with respiratory distress were supported with noninvasive ventilation. Neonates requiring intubation in the delivery room or fraction of inspired oxygen $\geq 0.3$ on noninvasive ventilation were given surfactant therapy. The full enteral feeding day was defined as the postnatal day achieving $120 \mathrm{~mL} / \mathrm{kg} / \mathrm{d}$ of milk feeding.

Neonates were classified into following five categories according to their TFTs. Normal-normal FT4 and TSH values in both initial and repeat tests. THOP-low FT4 and normal TSH in the initial test which got normalized on repeat test. THT-elevated TSH and normal FT4 in the initial test which got normalized on repeat test. Overt $\mathrm{CH}-$ elevated TSH and low FT4 in the initial test. Delayed TSH rise-normal FT4 and TSH in initial test and only elevated TSH in repeat test.

\section{Statistical Analysis}

All the quantitative parameters were represented by mean and standard deviation, and qualitative by frequency (percentage). For continuous variables, statistical analyses were performed using the $t$-test. The Pearson's chi-square test was used to compare categorical data. All the tests were significant at 5\% level of significance. Stata 15.1 (Stata Corp, Texas, United States) was used for analysis.

\section{Results}

Out of 117 eligible neonates, 96 completed the study. Twenty-one cases were excluded due to various factors such as death, inability to get the complete data, and denial of consent (-Fig. 1).

In the study group of 96 VLBW neonates, the mean gestational age was $30.5 \pm 2.7$ weeks and mean birth weight was $1,167 \pm 230 \mathrm{~g}$. The median (interquartile range) birth weight was 1,200 (317) $\mathrm{g}$, and the lowest survivor was $590 \mathrm{~g}$. Other characteristics are shown in - Table 1.

In our study, 30 neonates (31.2\%) had abnormal thyroid function. Among them, 10 (10.4\%) had THOP, 7 (7.3\%) had THT, 11 (11.5\%) had delayed TSH rise, and 2 (2.1\%) had overt $\mathrm{CH}$. The mean FT4 and TSH values at first and fourth weeks are shown in - Table 2.

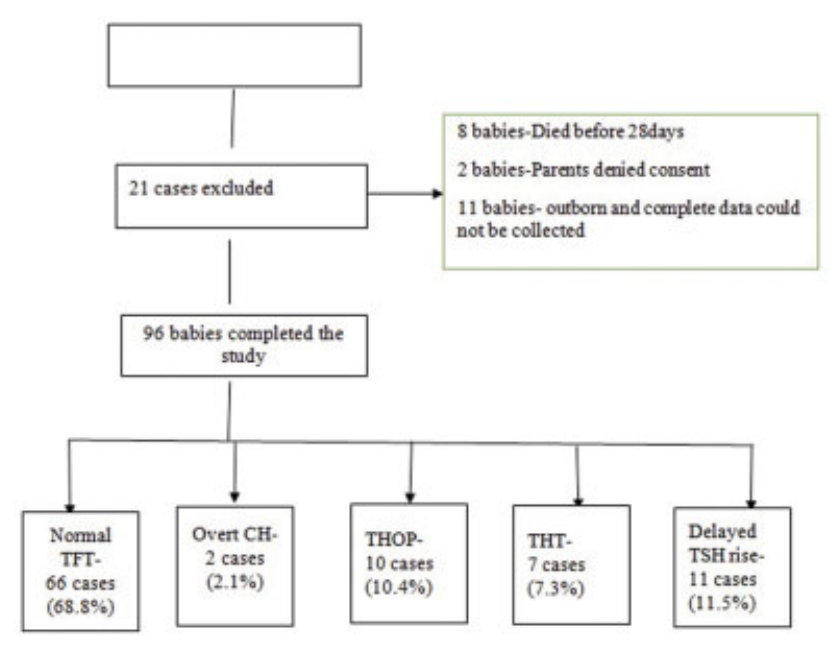

Fig. 1 Flow diagram of case selection and results. $\mathrm{CH}$, congenital hypothyroidism; TFT, thyroid function test; THOP, transient hypothyroxinemia of prematurity; THT, transient hyperthyrotropinemia; $\mathrm{TSH}$, thyroid-stimulating hormone. 
Table 1 Baseline characteristics of study population $(n=96)$

\begin{tabular}{|c|c|c|}
\hline Serial no. & Characteristics & Value \\
\hline 1 & $\begin{array}{l}\text { Birth weight in } \mathrm{g}, \text { mean (SD) } \\
\text { Birth weight in } \mathrm{g} \text {, Median (IQR) }\end{array}$ & $\begin{array}{l}1,167( \pm 230) \\
1,200(317)\end{array}$ \\
\hline \multirow[t]{3}{*}{2} & \multicolumn{2}{|l|}{ Birth weight distribution, $n(\%)$} \\
\hline & $<1,000 \mathrm{~g}$ & $23(24)$ \\
\hline & $1,000-1,499 \mathrm{~g}$ & $73(76)$ \\
\hline 3 & $\begin{array}{l}\text { Gestational age in wk, } \\
\text { mean (SD) }\end{array}$ & $30.5( \pm 2.7)$ \\
\hline \multirow[t]{5}{*}{4} & \multicolumn{2}{|l|}{ Gestational age distribution, $n$ (\%) } \\
\hline & $<28 w k$ & $15(15.6)$ \\
\hline & $28-32$ wk & $46(47.9)$ \\
\hline & $32-34$ wk & $30(31.3)$ \\
\hline & $>34 \mathrm{wk}$ & $5(5.2)$ \\
\hline \multirow[t]{2}{*}{5} & AGA, $n(\%)$ & $65(67.7)$ \\
\hline & SGA, $n(\%)$ & $31(32.3)$ \\
\hline 6 & Male sex, $n(\%)$ & $58(60.4)$ \\
\hline 7 & Cesarean section delivery, $n$ (\%) & $39(40.6)$ \\
\hline \multirow[t]{3}{*}{8} & \multicolumn{2}{|l|}{ Place of delivery, $n(\%)$} \\
\hline & Inborn & 69 (71.9) \\
\hline & Outborn & $27(28.1)$ \\
\hline \multirow[t]{3}{*}{9} & \multicolumn{2}{|l|}{ Antenatal steroid, $n(\%)$} \\
\hline & Complete course & $58(60.4)$ \\
\hline & Incomplete course & $15(15.6)$ \\
\hline
\end{tabular}

Abbreviations: AGA, appropriate for gestational age; IQR, interquartile range; SD, standard deviation; SGA, small for gestational age.

There were no significant differences among neonates with normal and abnormal thyroid functions with respect to gestational age, birth weight, gender, mode of delivery, Apgar score at 5 minutes, antenatal steroid therapy, surfactant therapy, invasive mechanical ventilation, noninvasive ventilation, and timing to full enteral nutrition ( - Table $\mathbf{3}$ ).

In serial TFT at 4 weeks, seven THOP neonates had normal TFT. Three THOP neonates had FT4 level still in the lower range of 0.9 to $1 \mathrm{ng} / \mathrm{dL}$ and normal TSH $(2.2-3.2 \mu \mathrm{U} / \mathrm{mL})$. TFT was repeated at 6 weeks of chronological age for these three neonates and was found to be normal. Neonates of THOP and THT groups were not treated, as repeat TFTs were within normal range during the study. Two neonates of $\mathrm{CH}$ were supplemented with levothyroxine within 1 week of life. At
4 weeks, repeat FT4 was within normal range. TSH was still elevated, although lower than previous values.

Among delayed TSH rise group, TSH was 10 to $13 \mu \mathrm{U} / \mathrm{mL}$ in 10 infants and $21 \mu \mathrm{U} / \mathrm{mL}$ in 1 neonate at 4 weeks. FT4 was normal in eight infants and low in three infants. Levothyroxine supplementation was started in these three infants with lower FT4. Repeat TFT at 6 weeks revealed normal FT4 and TSH in both treated and untreated cases of delayed rise of TSH. We continued supplementation in treated cases.

\section{Discussion}

The health statistics of India has improved tremendously in recent years, leading to survival of more premature and VLBW infants. Hence, this may be the right time to address morbidities in addition to mortality of infants. $\mathrm{CH}$ is among the few diseases which satisfies all criteria to be included in newborn screening program. Also, $\mathrm{CH}$ incidence is higher in India as compared with the global incidence. ${ }^{3}$ Unfortunately, mass screening of $\mathrm{CH}$ is yet to be established in India and pediatric endocrinologists are not readily available for expert opinion. TFTs - thyroxine (T4), FT4, and TSH in preterm neonates are interpreted based on gestational age-specific values. $^{9}$ When TSH-based thyroid screening within first week of life is practiced in preterm neonates, central hypothyroidism, thyroxine-binding globulin deficiency, THOP, and delayed TSH rise will not be identified. The use of onetime T4-based thyroid screening in preterm neonates will miss THT and delayed TSH rise. ${ }^{10}$ THOP and THT are selfexplanatory by their nomenclature-transient, resolve within 2 to 3 weeks with maturation of HPT axis. Hence, serial monitoring of both FT4 and TSH 2 to 4 weeks apart is considered as ideal to diagnose thyroid disorders among VLBW infants. ${ }^{11,12}$ But in a resource-limited country like ours, serial TFT every 2 weeks is not feasible. We performed TFT in the first week and repeated it after 4 weeks. Only those with abnormal test results at 4 weeks were subjected to repeat TFT at 6 weeks of age.

Almost one-third (31\%) of VLBW infants had abnormal TFTs in our study. Similar findings were observed by Kim et al, ${ }^{7}$ where $28.9 \%$ of preterm infants less than 32 weeks had thyroid dysfunction. ${ }^{13}$ However, Chung et al had found abnormal thyroid function in $46.6 \%$ preterm infants. ${ }^{14}$ The large variation in prevalence can be explained by variable

Table 2 Thyroid function tests results $(n=96)$

\begin{tabular}{|l|l|l|l|l|l|}
\hline $\begin{array}{l}\text { Thyroid function } \\
(\boldsymbol{n}=\mathbf{9 6})\end{array}$ & $\boldsymbol{n}(\%)$ & $\begin{array}{l}\text { First wk FT4 } \\
(\mathbf{n g} / \mathrm{dL})\end{array}$ & $\begin{array}{l}\text { First wk } \mathrm{TSH}^{\mathrm{a}} \\
(\boldsymbol{\mu U} / \mathrm{mL})\end{array}$ & $\begin{array}{l}\text { Fourth wk FT4 } \\
(\mathbf{n g} / \mathrm{dL})\end{array}$ & $\begin{array}{l}\text { Fourth }^{\mathrm{a} k} \\
(\boldsymbol{\mu U} / \mathrm{mL})\end{array}$ \\
\hline Normal & $66(68.8)$ & $1.46(0.43)$ & $3.64(1.88)$ & $1.35(0.26)$ & $4.45(2.13)$ \\
\hline CH & $2(2.1)$ & $0.24(0.26)$ & $64.83(49.73)$ & $1.12(0.35)$ & $71.47(40.34)$ \\
\hline THOP & $10(10.4)$ & $0.69(0.17)$ & $2.77(1.98)$ & $1.28(0.36)$ & $3.91(1.70)$ \\
\hline THT & $7(7.3)$ & $1.46(0.67)$ & $15.66(2.79)$ & $1.18(0.40)$ & $4.96(1.87)$ \\
\hline Delayed TSH rise & $11(11.5)$ & $1.24(0.40)$ & $4.26(3.49)$ & $1.41(0.35)$ & $11.87(1.66)$ \\
\hline
\end{tabular}

Abbreviations: $\mathrm{CH}$, congenital hypothyroidism; FT4, free thyroxine; THOP, transient hypothyroxinemia of prematurity; THT, transient hyperthyrotropinemia; TSH, thyroid-stimulating hormone.

a Values in mean (standard deviation). 
Table 3 Comparison of demographic variables between infants with normal and abnormal thyroid function tests

\begin{tabular}{|l|l|l|l|}
\hline Demographic variable & $\begin{array}{l}\text { Normal thyroid function } \\
(\boldsymbol{n}=\mathbf{6 6})\end{array}$ & $\begin{array}{l}\text { Abnormal thyroid } \\
\text { function }(\boldsymbol{n}=\mathbf{3 0})\end{array}$ & $p$-Value \\
\hline Gestational age in wk, mean (SD) & $30.7(2.6)$ & $30.0(2.9)$ & 0.243 \\
\hline Birth weight in g, mean (SD) & $1,179(227)$ & $1,141(240)$ & 0.464 \\
\hline Male sex, $n$ (\%) & $38(57.6)$ & $20(66.7)$ & 0.399 \\
\hline SGA, $n(\%)$ & $22(33.3)$ & $9(30)$ & 0.746 \\
\hline Cesarean section delivery, $n(\%)$ & $30(45.5)$ & $9(30)$ & 0.153 \\
\hline Complete antenatal steroid course, $n(\%)$ & $41(62.1)$ & $17(56.7)$ & 0.633 \\
\hline Apgar score at 5 min, mean (SD) & $7.4(1.3)$ & $7.1(1.1)$ & 0.282 \\
\hline Surfactant therapy, $n$ (\%) & $20(30.3)$ & $11(36.7)$ & 0.537 \\
\hline Invasive mechanical ventilation, $n(\%)$ & $22(33.3)$ & $9(30)$ & 0.746 \\
\hline Noninvasive ventilation, $n(\%)$ & $42(63.6)$ & $22(73.3)$ & 0.350 \\
\hline Full enteral feeding in d, mean (SD) & $14.3(7.2)$ & $13.4(7.1)$ & 0.586 \\
\hline
\end{tabular}

Abbreviations: SD, standard deviation; SGA, small for gestational age.

criteria used for defining thyroid dysfunction among clinical studies. It is difficult to predict clinically which infant may develop thyroid dysfunction because demographic factors are similar in both normal and abnormal thyroid function groups as found in - Table 3 .

In our study, $10.4 \%$ of VLBW neonates had transient hypothyroxinemia. Similar findings were seen by Lee et al who studied 246 VLBW infants and found transient hypothyroxinemia in $7.3 \%$ infants. ${ }^{15}$ About $20 \%$ of preterm infants $<34$ weeks and $29 \%$ of VLBW infants with gestational age $<33$ weeks had transient hypothyroxinemia in studies by Delahunty et al and Dilli et al, respectively. ${ }^{16,17}$ The large variation is due to difference in number of extreme premature infants in the study populations along with different cutoff levels used for TSH and FT4 values. Perlman and Gressens et al found that low serum concentration of thyroid hormone in the early period of life is associated with poor developmental outcomes. ${ }^{18,19}$ However, the randomized controlled trials of thyroid hormone supplementation in THOP have failed to show any beneficial effects in improving neurologic outcomes or reducing morbidity. ${ }^{20,21}$ THT was found in $7.3 \%$ of VLBW neonates in our study as agreement to $16 \%$ in Armanian et al. ${ }^{8}$ Another study involving 622 preterm neonates found hyperthyrotropinemia with normal TSH in 35 (5.6\%) neonates. ${ }^{22}$ THT may be due to inability of the thyroid gland of premature infants to cope with external iodine overload, and thyroid function is more likely to normalize on re-evaluation. ${ }^{13,23,24}$

Eleven (11.5\%) neonates had delayed TSH rise at 4 weeks of age in our study. In a retrospective analysis by Kaluarachchi et al involving 286 premature infants $<30$ weeks of gestation, delayed TSH elevation was diagnosed in 20 infants $(6.9 \%){ }^{25}$ In another study involving 3,137 preterm infants born at 22 to 31 weeks of gestation, delayed TSH elevation was found in 45 infants $(1.43 \%){ }^{26}$ The optimal timing of repeat screen is still debated. McGrath et al found that $50.9 \%$ preterm infants born at $<33$ weeks of gestation who were diagnosed with $\mathrm{CH}$ had delayed TSH elevation and would have been missed on first newborn screen. ${ }^{27}$ If screening had been repeated at only 2 weeks of life, $48 \%$ infants with delayed TSH elevation would have been undetected. Hence, repeat screen at least once after 4 weeks of life may be strongly suggested in premature infants. It is not known whether this type of $\mathrm{CH}$ with delayed rise of TSH is transient or permanent. ${ }^{13,28,29}$ The benefit of thyroid hormone supplementation in delayed TSH group is also not clear. ${ }^{30,31}$ Hence, we started levothyroxine supplementation only in infants with low FT4. Two infants had overt $\mathrm{CH}$ in our study. They were treated and followed up using the standard American Academy of Pediatrics guideline. ${ }^{12}$ Compared with previous studies, there is higher incidence of delayed TSH, CH among VLBW neonates in our study. The higher incidence of thyroid disorder in our part of the world could be due to incomplete iodization, leading to maternal iodine deficiency.

There are several limitations in the present study. The study had relatively small sample size and was monocentric. Maternal characteristics including maternal TFT, and effect of neonatal medications and blood transfusions on preterm thyroid function were not analyzed. Further studies involving large sample sizes from multiple centers are needed to determine the timing, frequency of TFTs, and universal cutoff values for FT4 and TSH in preterm infants.

\section{Conclusion}

Almost one-third of VLBW infants have thyroid dysfunction and their demographic profile is unable to predict thyroid dysfunction. In resource-limited settings, repeat TFTs at least once after 4 weeks of age may be suggested to identify delayed rise of TSH, which may need intervention.

\section{Conflict of Interest}

None declared. 
Acknowledgments

We thank Dr. Mona Pathak, assistant professor, Department of Biostatistics, KIMS, Bhubaneswar for providing statistical guidance during data analysis.

\section{References}

1 Simoneau-Roy J, Marti S, Deal C, Huot C, Robaey P, Van Vliet G. Cognition and behavior at school entry in children with congenital hypothyroidism treated early with high-dose levothyroxine. J Pediatr 2004;144(06):747-752

2 LaFranchi SH. Newborn screening strategies for congenital hypothyroidism: an update. J Inherit Metab Dis 2010;33(Suppl 2): S225-S233

3 ICMR Task Force on Inherited Metabolic Disorders. Newborn screening for congenital hypothyroidism and congenital adrenal hyperplasia. Indian J Pediatr 2018;85(11):935-940

4 van Wassenaer AG, Kok JH. Hypothyroxinaemia and thyroid function after preterm birth. Semin Neonatol 2004;9(01):3-11

5 LaFranchi S. Thyroid function in the preterm infant. Thyroid 1999; 9(01):71-78

6 Fisher DA. Thyroid function and dysfunction in premature infants. Pediatr Endocrinol Rev 2007;4(04):317-328

7 Kim HR, Jung YH, Choi CW, Chung HR, Kang MJ, Kim BI. Thyroid dysfunction in preterm infants born before 32 gestational weeks. BMC Pediatr 2019;19(01):391

8 Armanian AM, Kelishadi R, Barekatain B, Salehimehr N, Feizi A. Frequency of thyroid function disorders among a population of very-low-birth-weight premature infants. Iran J Neonatol 2016;7 (03):9-16

9 Williams FL, Simpson J, Delahunty C, et al; Collaboration from the Scottish Preterm Thyroid Group. Developmental trends in cord and postpartum serum thyroid hormones in preterm infants. J Clin Endocrinol Metab 2004;89(11):5314-5320

10 Desai MP, Sharma R, Riaz I, Sudhanshu S, Parikh R, Bhatia V. Newborn screening guidelines for congenital hypothyroidism in India: recommendations of the Indian Society for Pediatric and Adolescent Endocrinology (ISPAE) - Part I: screening and confirmation of diagnosis. Indian J Pediatr 2018;85(06):440-447

11 Léger J, Olivieri A, Donaldson M, et al; ESPE-PES-SLEP-JSPE-APEGAPPES-ISPAE Congenital Hypothyroidism Consensus Conference Group. European Society for Paediatric Endocrinology consensus guidelines on screening, diagnosis, and management of congenital hypothyroidism. J Clin Endocrinol Metab 2014;99(02):363-384

12 Rose SR, Brown RS, Foley T, et al; American Academy of Pediatrics Section on Endocrinology and Committee on Genetics, American Thyroid Association Public Health Committee, Lawson Wilkins Pediatric Endocrine Society. Update of newborn screening and therapy for congenital hypothyroidism. Pediatrics 2006;117(06): 2290-2303

13 Woo HC, Lizarda A, Tucker R, et al. Congenital hypothyroidism with a delayed thyroid-stimulating hormone elevation in very premature infants: incidence and growth and developmental outcomes. J Pediatr 2011;158(04):538-542

14 Chung HR, Shin CH, Yang SW, et al. High incidence of thyroid dysfunction in preterm infants. J Korean Med Sci 2009;24(04): 627-631
15 Lee JH, Kim SW, Jeon GW, Sin JB. Thyroid dysfunction in very low birth weight preterm infants. Korean J Pediatr 2015;58(06): 224-229

16 Delahunty C, Falconer S, Hume R, et al; Scottish Preterm Thyroid Group. Levels of neonatal thyroid hormone in preterm infants and neurodevelopmental outcome at $51 / 2$ years: millennium cohort study. J Clin Endocrinol Metab 2010;95(11):4898-4908

17 Dilli D, Eras Z, Andiran N, Dilmen U, Sakrucu ED. Neurodevelopmental evaluation of very low birth weight infants with transient hypothyroxinemia at corrected age of 18-24 months. Indian Pediatr 2012;49(09):711-715

18 Perlman JM. Neurobehavioral deficits in premature graduates of intensive care-potential medical and neonatal environmental risk factors. Pediatrics 2001;108(06):1339-1348

19 Gressens P, Rogido M, Paindaveine B, Sola A. The impact of neonatal intensive care practices on the developing brain. J Pediatr 2002;140(06):646-653

20 Valerio PG, van Wassenaer AG, de Vijlder JJ, Kok JH. A randomized, masked study of triiodothyronine plus thyroxine administration in preterm infants less than 28 weeks of gestational age: hormonal and clinical effects. Pediatr Res 2004;55(02):248-253

21 Osborn DA. Thyroid hormones for preventing neurodevelopmental impairment in preterm infants. Cochrane Database Syst Rev $2001 ;(04): C D 001070$

22 Chung ML. Incidence and risk factor of permanent hypothyroidism in preterm infants. J Neonatal Biol 2017;6:254

23 Chung ML, Yoo HW, Kim KS, et al. Thyroid dysfunctions of prematurity and their impacts on neurodevelopmental outcome. J Pediatr Endocrinol Metab 2013;26(5-6):449-455

24 Zung A, Tenenbaum-Rakover Y, Barkan S, et al. Neonatal hyperthyrotropinemia: population characteristics, diagnosis, management and outcome after cessation of therapy. Clin Endocrinol (Oxf) 2010;72(02):264-271

25 Kaluarachchi DC, Colaizy TT, Pesce LM, Tansey M, Klein JM. Congenital hypothyroidism with delayed thyroid-stimulating hormone elevation in premature infants born at less than 30 weeks gestation. J Perinatol 2017;37(03):277-282

26 Kaluarachchi DC, Allen DB, Eickhoff JC, Dawe SJ, Baker MW. Increased congenital hypothyroidism detection in preterm infants with serial newborn screening. J Pediatr 2019;207:220-225

27 McGrath N, Hawkes CP, Mayne P, Murphy NP. Optimal timing of repeat newborn screening for congenital hypothyroidism in preterm infants to detect delayed thyroid-stimulating hormone elevation. J Pediatr 2019;205:77-82

28 Vigone MC, Caiulo S, Di Frenna M, et al. Evolution of thyroid function in preterm infants detected by screening for congenital hypothyroidism. J Pediatr 2014;164(06):1296-1302

29 Srinivasan R, Harigopal S, Turner S, Cheetham T. Permanent and transient congenital hypothyroidism in preterm infants. Acta Paediatr 2012;101(04):e179-e182

30 Lafranchi SH. Congenital hypothyroidism: delayed detection after birth and monitoring treatment in the first year of life. J Pediatr 2011;158(04):525-527

31 Deladoëy J, Ruel J, Giguère Y, Van Vliet G. Is the incidence of congenital hypothyroidism really increasing? A 20-year retrospective population-based study in Québec. J Clin Endocrinol Metab 2011;96(08):2422-2429 